\title{
Improvement of hydrodynamic forecasting of Danish waters: impact of low-frequency North Atlantic barotropic variations
}

\author{
Bjarne Büchmann • Carsten Hansen • Johan Söderkvist
}

Received: 28 January 2011 / Accepted: 9 June 2011 / Published online: 29 June 2011

(C) The Author(s) 2011. This article is published with open access at Springerlink.com

\begin{abstract}
The Danish Maritime Safety Administration (DaMSA) provides forecast of elevations, currents, and other parameters to the maritime society. Accurate and reliable predictions are important to help navigate Danish waters in a safe manner, and the forecasts are routinely used by the Vessel Traffic Services in the Great Belt and the Sound. The DaMSA model setup includes three nested models, with coarse resolution in the North Atlantic and increasing to $600 \mathrm{~m}$ in the Belt Sea and South West Baltic. Observations of some special events in late 2009 drew attention to a possible relation between Atlantic-scale surge events and small-scale currents in the Danish Straits. During the special event with large-scale surge, the observed southward moving current in the Danish Straits was $0.5-2.0 \mathrm{~m} / \mathrm{s}$ for several days, while the operational model showed a much smaller response. As a consequence, the entire DaMSA model complex was revised during 2010. Multi-annual reruns have showed that with the updated model, the explained variance of the current increases from $67 \%$ to $88 \%$.
\end{abstract}

Keywords Ocean modeling · Flather - Inverse Barometric . Operational

Responsible Editor: Chari Pattiaratchi

This article is part of the Topical Collection on Physics of Estuaries and Coastal Seas 2010

B. Büchmann $(\bowtie) \cdot C$. Hansen · J. Söderkvist

Danish Maritime Safety Administration (DaMSA),

Copenhagen, Denmark

e-mail: bjb@frv.dk

C. Hansen

e-mail: cha@frv.dk

J. Söderkvist

e-mail: jos@frv.dk

URL: http://frv.dk/

\section{Introduction}

A suite of nested setups of the General Estuarine Transport Model, GETM (Burchard et al. 2009, 2010), is in operational forecasting use at DaMSA. The setups include a barotropic surge model of the North Atlantic with a horizontal resolution of $3 \mathrm{~nm}(N A 3)$ and two baroclinic models with 60 vertical layers: an outer setup covering the North Sea-Baltic Sea area in $1 \mathrm{~nm}$ resolution $($ NSIC), and an inner setup with $600 \mathrm{~m}$ horizontal resolution that covers the Danish straits (DK600; see Fig. 1). The forecasts are used to improve safety at sea by providing online information for mariners (DaMSA 2010a, b). Therefore, the skills of the model are important, and work at DaMSA includes periodic validation of the GETM model results against in situ observations; see, e.g., Hansen and Söderkvist (2010). It is well established that the model results generally yield highquality forecasts. However, in 2009, it was observed that there were periods of up to 10 days where there was significant error on the predictions of current in the Danish straits. As a consequence, a major revision of the entire model hierarchy was undertaken during 2010.

In the present paper, the major model changes made to improve the modeling skills will be presented. It will be demonstrated that the modeled elevations and currents in the inner domain (DK600) are significantly influenced by the choice of boundary conditions used on the outer domains. The influence is significant, even when the outer-domain boundaries are located thousands of kilometers from the area of interest and may seem "very remote" when compared to the scale of the straits, which is in the order of $10 \mathrm{~km}$.

In the following section, the various setups of GETM and the changes in the setups that resulted in the model improvements are presented. In Section 3, the results of three hindcast simulations are presented. Discussions and 
Fig. 1 Model setup for three nested domains running operationally at DaMSA: $3 \mathrm{~nm}$ barotropic surge model (NA3), and $1 \mathrm{~nm}$ (NS1C) and $600 \mathrm{~m}$ (DK600) 60 layer baroclinic models. In situ stations are marked for clarity: Wick (A), Skagen (B), Grenaa (C), Viken (D), Roedvig (E), Gedser (F), and Vengeance Ground (G)

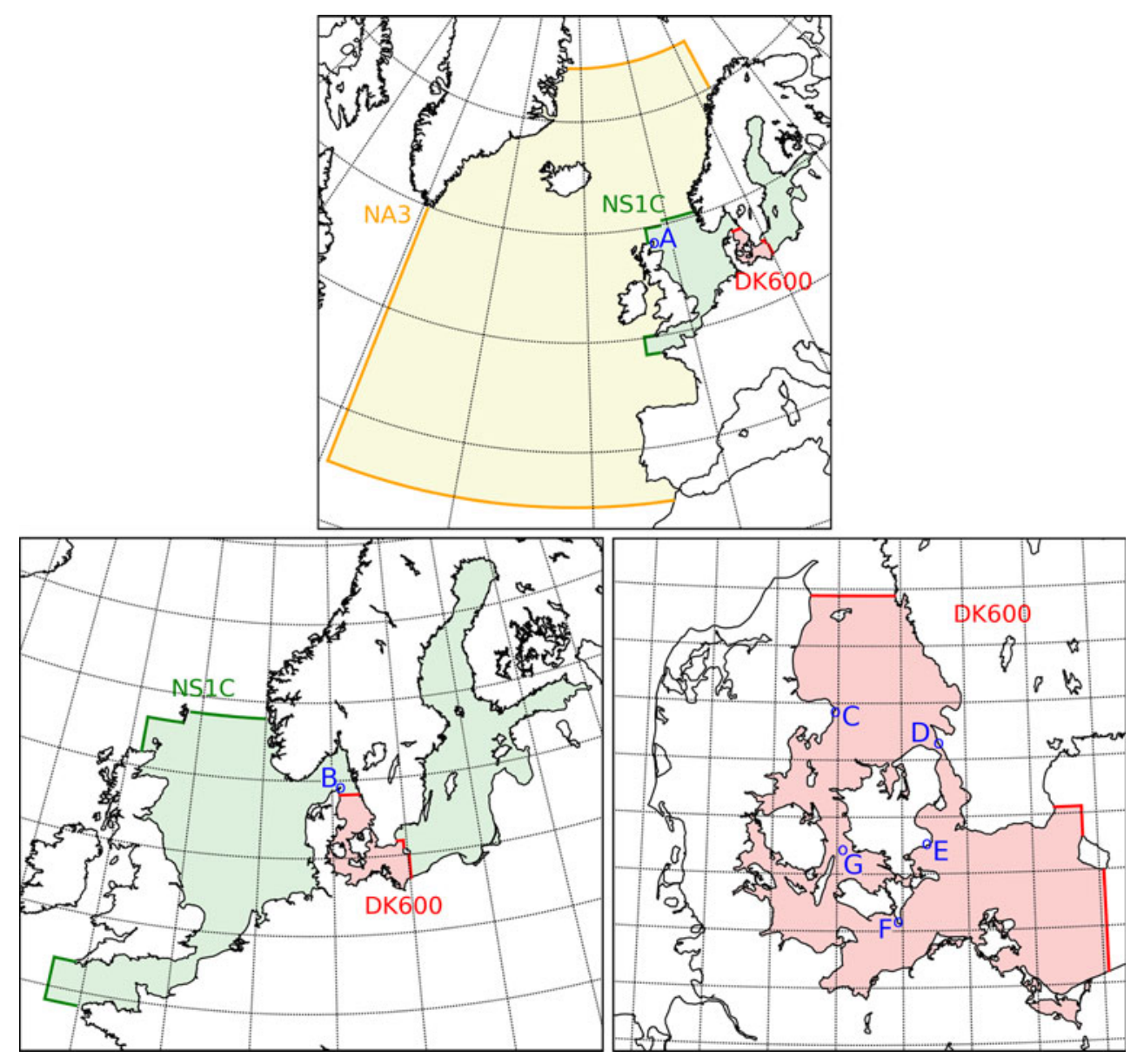

future outlook are given in Section 4, while Conclusions are presented in Section 5.

\section{Model setups}

GETM has been used as an operational model at DaMSA since 2007, originally in a stand-alone 1-nm baroclinic model (NS1C; see Fig. 1) with 60 vertical layers throughout the region. Elevation boundary conditions were predictions of astronomical tidal signal (Andersen 2006) applied in socalled clamped configuration. The bathymetry in the northwest part of the North Sea was tuned to improve the tidal signal into the Danish waters. The introduction of the North-Atlantic surge model (NA3) in 2008 provided a clear improvement of the modeling results, as the wind-generated setup over the Northeast Atlantic was now included. The surges from the NA3 model were added linearly to the tidal prediction, and the sum was used for improved clamped boundary conditions for NS1C. The choice of boundary conditions for the NA3 model was influenced by stability considerations and the implementation available at the time. Several versions were tested, and the optimal choice at the time was a no-flow condition combined with a wide numerical beach to absorb outgoing waves. Further, general smoothing was applied in the domain to increase dissipation of spurious short-periodic waves. During summer of 2009, a 600-m 60-layer baroclinic model (DK600) was introduced to better resolve the currents in the narrow Danish straits. At this time, the GETM code base had progressed, and the nesting from NS1C was made with a Flather-style boundary condition (Carter and Merrifield 2007). The Flather condition is a radiation boundary condition, which requires prescribed elevation and barotropic normal velocity of the incoming wave. The combination of models (NA3, NS1C , and DK600) and boundary conditions described here were in operational production until late 2010 and will be denoted "Old Prod" in the present work.

To improve the performance of the model suite, a large number of annual hindcast simulations were undertaken to tune the parameters and boundary conditions of the models. The result is an updated model suite, which will be denoted "New Prod." The underlying code base of NA3 and NS1C has been updated to allow, e.g., Flather conditions. The boundary condition of NA3 has been changed to a Flather condition, combining so-called inverse barometric effect (Ponte et al. 1991) and an estimate for steric height changes 
due to seasonal variations in temperature and salinity (e.g., Ivchenko et al. 2007). As the pressure-bound waves move with the atmospheric pressure systems much slower than free shallow water waves, the target velocity for the Flather condition is set to zero. Tuning the steric effect showed best results for an annual harmonic with an amplitude of $0.06 \mathrm{~m}$ and zero down-crossing at New Year. The smoothing was significantly reduced over most of the domain, retaining significant dissipation only along the outer boundaries. Also in the NS1C model, the boundary conditions were changed to Flather type. Thus, the velocity components of the astronomical tidal waves were needed on the boundary. The OSU tidal data inversion (Egbert and Erofeeva 2002) has been used with the high-resolution dataset (Regional Tidal Solutions for the European Shelf, COAS 2010). In addition, the bathymetry of the NS1C model has been changed slightly to tune the tidal propagation inside the model with the updated boundary conditions. The DK600 model was not changed as part of the update.

In order to quantify the effect of the open boundary conditions of the NA3 model on the hydrodynamics, a "Control Test" model suite has also been examined. The Control Test is configured as New Prod, except that the boundary conditions of $N A 3$ are implemented with numerical beach and zero-flux condition as in Old Prod and that the bathymetry of NSIC is left un-tuned.

\section{Results}

The model performances for three nested suites described in Section 2 are evaluated by comparison to in situ observations. Elevation measurements from six coastal stations and surface current measurements from a single buoy station are used. The location of each station is shown on Fig. 1.

\subsection{Statistical properties, 2009}

Three statistical quantities are computed to evaluate the quality of the modeled elevation: correlation coefficient, root mean square error (RMSE), and explained variance (Ev). The Ev is defined as

$\mathrm{Ev}=1-\frac{\operatorname{var}(\text { obs. }- \text { mod. })}{\operatorname{var}(\text { obs. })}$,

where obs. is time series of the observed value, mod. is time series of the model result, and var is the variance of a time series. In the narrow Danish straits, the current is often nearly bidirectional, i.e., with strongly dominant main direction. Therefore, the quality of modeled current is evaluated by mean direction and by Ev and RMSE in current projected on mean direction. Also, current roses are examined. Statistical values for the NA3 and NS1C setups are calculated for the entire year 2009. For the stations that are situated within the DK600 domain, the statistics are made from July 12, 2009 when the DK600 model was introduced in Old Prod.

In the present work, the explained variance will be used as the main statistical parameter (see Table 1). Results for root mean square error (Table 2) and correlation coefficient (Table 3) are included for completeness.

At Wick in Scotland, near the northern boundary of NSIC, the influence of the new setup for the Atlantic model (NA3) is evaluated through the results of the Control Test. It should be noted that since the Wick tide gauge data are compared to the NA3 setup without tidal information, the observed data are low-pass filtered (Beardsley et al. 1983; Beardsley 2005) prior to the computation of the statistical quantities. For the Wick station, the updated GETM code base and decrease of the overall dissipation present in the Control Test increase the explained variance from $41 \%$ to $60 \%$ (see Table 1). When a Flather boundary condition based on inverse barometric effect and steric height is introduced in the NA3 setup (New Prod), the result further improves to $90 \%$ explained variance.

Also, for the elevation stations in Skagerrak and Kattegat (Skagen, Grenaa, Viken) in the inner Danish waters, there is a significant increase in the explained variance, while there is only a very small improvement for the stations in the southwestern part of the Baltic (Gedser, Roedvig). These latter stations lie behind the narrow and shallow Danish straits, which increasingly dampens the response with increasing frequency of the sea level oscillations in Kattegat. Oscillations with a period of 3 months or more pass the straits practically undamped, while oscillations at tidal frequency are almost completely absent in the southwestern Baltic.

In the Danish straits, the main direction of the current is largely determined by the local bathymetry, thus being

Table 1 Explained variance [\%] of elevation for 2009 at selected stations for the three model suites

\begin{tabular}{lllll}
\hline Station & Model setup & Old prod & Control test & New prod \\
\hline Wick & NA3 & 41 & 60 & 90 \\
Skagen & NS1C & 70 & 77 & 90 \\
Grenaa $^{\mathrm{a}}$ & DK600 & 73 & 75 & 86 \\
Viken $^{\mathrm{a}}$ & DK600 & 71 & 70 & 84 \\
Gedser $^{\mathrm{a}}$ & DK600 & 91 & 88 & 92 \\
Roedvig $^{\mathrm{a}}$ & DK600 & 87 & 85 & 91 \\
\hline
\end{tabular}

Observations from Wick are obtained from BODC (2010) and are filtered with a 33-h low pass filter pl33tn. Viken data are from BOOS (2010), and remaining in-situ data from DaMSA (2010b)

${ }^{\text {a }}$ The period covered is $20097-12$ to $12-31$ 
Table 2 Root Mean Square Error [m] of elevation for 2009 at selected stations for the three model suites

\begin{tabular}{llccc}
\hline Station & Model setup & Old prod & Control test & New prod \\
\hline Wick & NA3 & 0.130 & 0.086 & 0.040 \\
Skagen & NS1C & 0.120 & 0.090 & 0.060 \\
Grenaa $^{\mathrm{a}}$ & DK600 & 0.101 & 0.103 & 0.077 \\
Viken $^{\mathrm{a}}$ & DK600 & 0.086 & 0.087 & 0.065 \\
Gedser $^{\mathrm{a}}$ & DK600 & 0.070 & 0.080 & 0.064 \\
Roedvig $^{\mathrm{a}}$ & DK600 & 0.070 & 0.077 & 0.061 \\
\hline
\end{tabular}

Observations from Wick are obtained from BODC (2010) and are filtered with a 33-h low pass filter pl33tn. Viken data are from BOOS (2010), and remaining in-situ data from DaMSA (2010b)

${ }^{\text {a }}$ The period covered is $20097-12$ to $12-31$

North-South at Vengeance Ground in the Great Belt. The observed main direction was $5.6^{\circ}$, while the modeled main direction (New Prod DK600) is $0.1^{\circ}$ (see Table 4). In Fig. 2, the current roses for observations and New Prod are compared. It is noted that major features such as strong southward currents (into the Baltic and with speed larger than $1.25 \mathrm{~m} / \mathrm{s}$ ), are well reproduced. The largest difference is a small shift in the main direction of the southward currents.

The prediction of current in the DK600 model increases significantly (from $67 \%$ to $88 \%$ ) with the New Prod setup compared to Old Prod (see Table 4). Interestingly, though, the increase does not seem to be directly related to the updated boundary condition on the NA3 model: the Control Test shows almost as good statistics as does the New Prod setup.

\subsection{Special event, November 2009}

In this section, we present the model improvement for the time period ultimo 2009 when there were significant errors in the current predictions of Old Prod. During the period, there was an exceptionally deep and extended low pressure over the

Table 3 Correlation Coefficient [-] of elevation for 2009 at selected stations for the three model suites

\begin{tabular}{llccc}
\hline Station & Model setup & Old prod & Control test & New prod \\
\hline Wick & NA3 & 0.64 & 0.78 & 0.95 \\
Skagen & NS1C & 0.84 & 0.88 & 0.95 \\
Grenaa $^{\mathrm{a}}$ & DK600 & 0.86 & 0.88 & 0.93 \\
Viken $^{\mathrm{a}}$ & DK600 & 0.86 & 0.85 & 0.92 \\
Gedser $^{\mathrm{a}}$ & DK600 & 0.95 & 0.94 & 0.96 \\
Roedvig $^{\mathrm{a}}$ & DK600 & 0.93 & 0.93 & 0.95 \\
\hline
\end{tabular}

Observations from Wick are obtained from BODC (2010) and are filtered with a 33-h low pass filter pl33tn. Viken data are from BOOS (2010), and remaining in-situ data from DaMSA (2010b)

${ }^{\text {a }}$ The period covered is $20097-12$ to $12-31$
Table 4 Statistical values Vengeance at $1.0 \mathrm{~m}$ depth for three experiments: Old Prod, Control Test, and New Prod

\begin{tabular}{lccc}
\hline & Old prod & Control test & New prod \\
\hline $\begin{array}{l}\text { Explained variance along } \\
\text { the main direction (\%) }\end{array}$ & 67 & 86.4 & 88.3 \\
$\begin{array}{l}\text { Error in main direction }\left({ }^{\circ}\right) \\
\text { RMSE along the main }\end{array}$ & -5.1 & -4.8 & -5.5 \\
direction $\left[\mathrm{m} \mathrm{s}^{-1}\right.$ ] & 0.33 & 0.21 & 0.20 \\
\hline
\end{tabular}

Time period to compute the statistical values are 2009 7-12 to $12-31$. Observations are from DaMSA (2010b)

Northeastern Atlantic. For details and MSLP weather chart, see, e.g., MetOffice (2010). The observed elevation at Wick (low-pass filtered) increased from 2.0 to almost $2.8 \mathrm{~m}$ from November 11th to November 23rd (see Fig. 3). In the same period, the model results from the NA3 Old Prod setup varied between 2.0 and $2.2 \mathrm{~m}$, increasing to $2.4 \mathrm{~m}$ on the $23 \mathrm{rd}$. The New Prod simulates the elevation at Wick much better, with errors less than $0.2 \mathrm{~m}$ between the 18th and 22th November. On the 23rd, when the observed elevation peaked, the model error is still only around $0.2 \mathrm{~m}$. This improvement of the model results is attributed mainly to the updated (Flather) boundary condition on the outer boundaries of NA3. The lowpressure systems represent an anomaly of around $40 \mathrm{hPa}$ over large areas of the Northeastern Atlantic, corresponding to an increased water level of about $0.4 \mathrm{~m}$. The no-flux conditions on Old Prod prohibits such a general water rise in the entire region, while it is included in New Prod.

The high elevation spreads into the North Sea and further into Kattegat. Elevation at Grenaa in Kattegat is also affected by local wind and effects from baroclinic fronts, which makes it difficult to isolate the surge. From the 14th to the 19th of November, the observed elevation at Grenaa increased from about -0.4 to $+0.5 \mathrm{~m}$ (Fig. 4). Except for a tidal low, the observed elevation continued to be above $0.0 \mathrm{~m}$ until the 24th. The elevation in Old Prod was 0.2 to $0.35 \mathrm{~m}$ below observations for most of the time during the period 14-24 of November (see Fig. 4), the main part of the error being attributed to the Northeast Atlantic surge missed in Old Prod NA3. The New Prod catches the increase near the 15th of November much better, and during the time period with observed high values, New Prod has error values less than $0.1 \mathrm{~m}$.

At station Gedser in the southwestern part of the Baltic, a large part of the tidal signal from the north is filtered out by the narrow and shallow Danish Straits. Here, the elevation is determined more by local wind and the low frequency part of the variability in elevation north of the Danish Straits, and as can be seen from Fig. 5, there is no significant increase in water level in the observations from November 15 th to 18 th. However, on November 18th, there is a rapid decrease in elevation of nearly $1 \mathrm{~m}$ to an extreme 

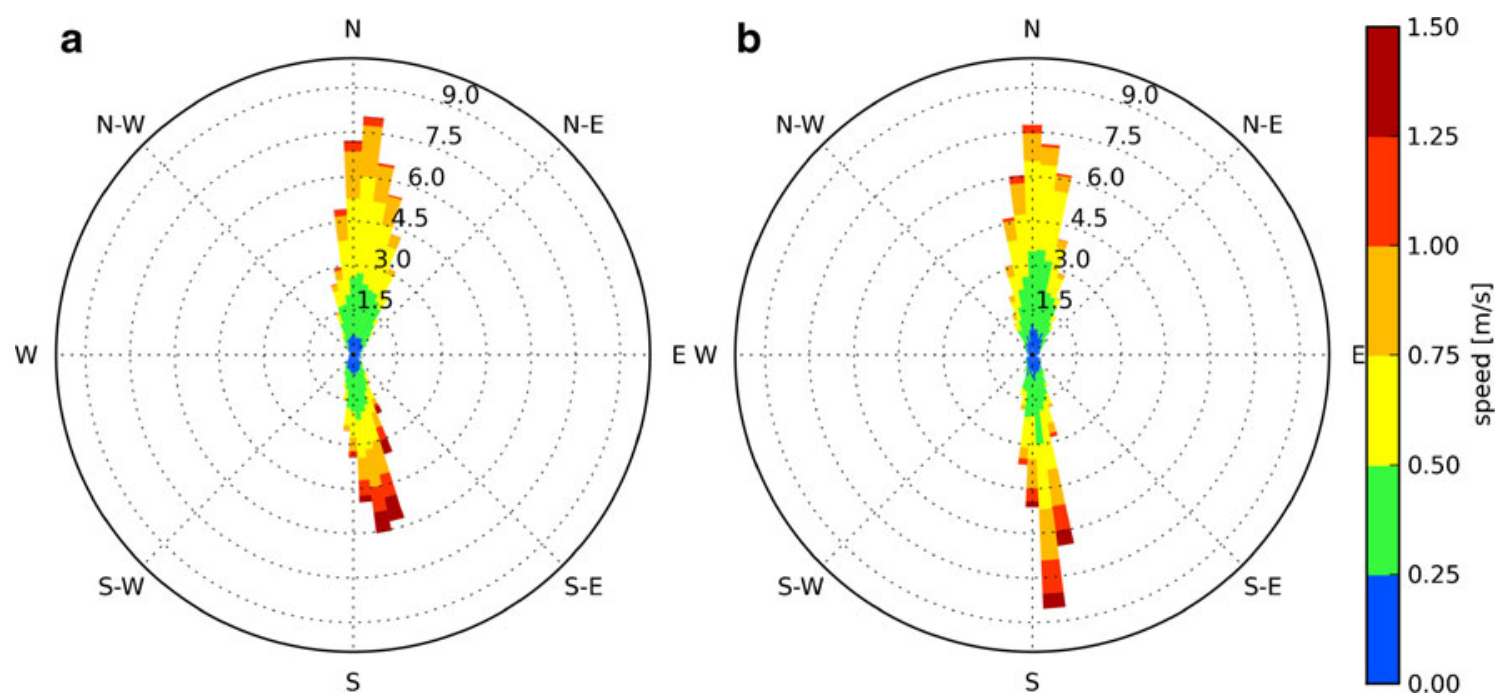

Fig. 2 Current rose at Vengeance in Great Belt at $1.0 \mathrm{~m}$ depth for 2009, a observed (DaMSA 2010b), and b New Prod (DK600 setup)

low of $-1.2 \mathrm{~m}$, followed by a rapid increase of $1.3 \mathrm{~m}$ early 19th November. This spike is attributed to the strong winds connected to the major low-pressure system acting locally on the Western Baltic water. The water is pushed east and north towards the Baltic Sea proper leading to a sharp decline in the local water level. Subsequently, with the slack of the winds, the water is released and rushed back to the area in a seiche-type effect. This type of seiche is well known, and the range $(1.3 \mathrm{~m})$ corresponds roughly to a 20 $\mathrm{m} / \mathrm{s}$ wind acting on the Baltic proper (see, e.g., Feistel et al. 2008). Both Old Prod and New Prod simulate this effect rather well (Fig. 5). The largest errors occur at the extreme low water event, with errors of about $0.2 \mathrm{~m}$.

Currents in the Danish Straits are often to a large extent driven by the difference in elevation north and south of the strait. During the event in the middle of November, the elevation in Kattegat had mainly positive values (Fig. 4), while south of the Danish Straits, the elevation was mainly below $0.1 \mathrm{~m}$ (see Fig. 5). The difference in elevation generated southward moving currents. At Vengeance Ground, the observed current was between -0.5 and

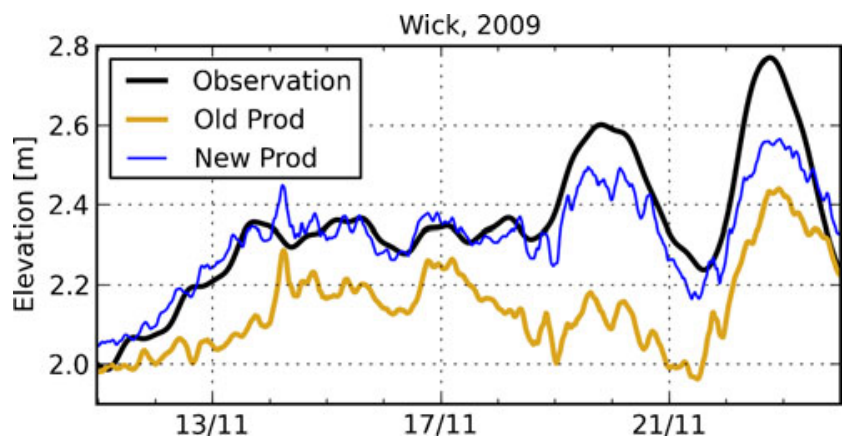

Fig. 3 Elevation at Wick, observed (BODC, 2010), Old Prod, and New Prod. Observed elevation was filtered with a 33-h low pass filter pl33tn. Model results are from the NA3 setup
$-2.0 \mathrm{~m} / \mathrm{s}$ between 15th and 22th of November (Fig. 6). The mechanism that generated the southward current for several days was the high elevation in Kattegat (Fig. 4). The peak value of $-2.0 \mathrm{~m} / \mathrm{s}$ on the 19th (Fig. 6) seems, however, mostly connected to the extreme low water value in Western Baltic (Fig. 5). As the Old Prod model underestimates the water level in Kattegat, it also underestimates the local current in the Great Belt. The New Prod captures the inflow better, leading to an increase in the modeled current of around $0.4 \mathrm{~m} / \mathrm{s}$. The strongest observed current of about $-2.0 \mathrm{~m} / \mathrm{s}$ is predicted by New Prod to be $-1.5 \mathrm{~m} / \mathrm{s}$, but the period with large error is very short (see Fig. 6). For the other time periods, the New Prod simulated the current at Vengeance Ground very well, both the tidal fluctuations and the prevailing southward moving current.

\section{Discussion and future work}

The process of model improvement of the GETM setup at DaMSA was initiated by large reported model errors in

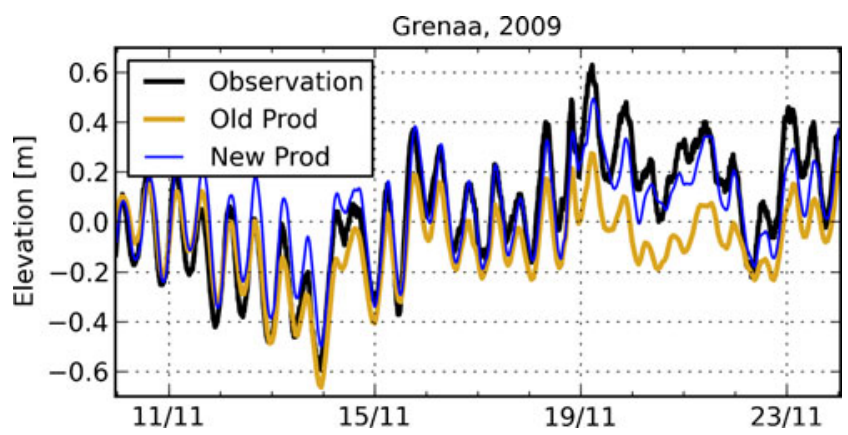

Fig. 4 Elevation at Grenaa observed, Old Prod, and New Prod Observations are from DaMSA (2010b). Model results are from the DK600 setup 


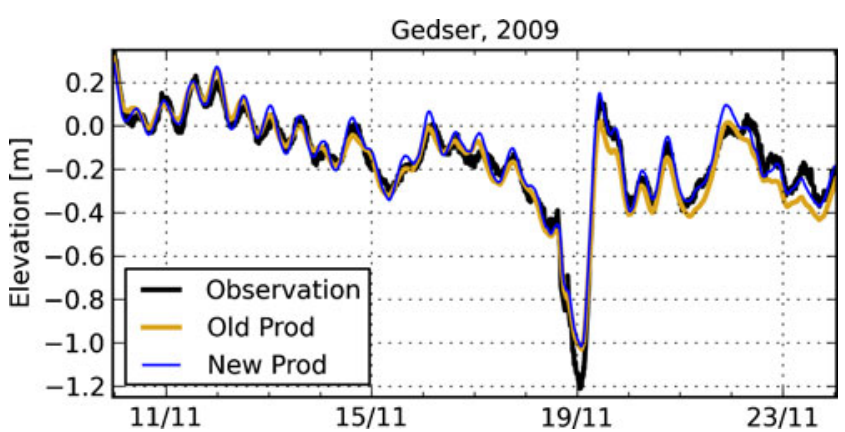

Fig. 5 Elevation at Gedser observed Old Prod, and New Prod Observations are from DaMSA (2010b). Model results are from the DK600 setup

elevation and current during a specific event in November 2009. For this time period, there was a strong meteorological forcing in the North Atlantic that generated an increased elevation in the North Sea-Kattegat area that was underestimated by the model. Improvement of the boundary conditions in the North Atlantic surge model setup, NA3, resulted in a much better simulation of elevation for the inner Danish waters - both for the special event in November 2009 and for the statistical properties for the entire year of 2009. Other changes, such as codebased updates and updated boundary condition type on the $1 \mathrm{~nm}$ baroclinic model (NSIC), contributed to increased accuracy of local current prediction in the Danish straits. The improved predictions of barotropic surges lasting several days also influence the prediction of these currents in a positive way.

Although the model improvements presented in the present paper significantly increase the explained variance of both elevation and current, it seems possible to improve the results even further: there are still periods where New Prod model elevation and currents differ significantly from observations, which will require even further model improvements. Also, the explained variance of elevation does decrease from Skagen to Viken (see Table 1), and at least part of this is due to inaccuracies in the modeled tidal

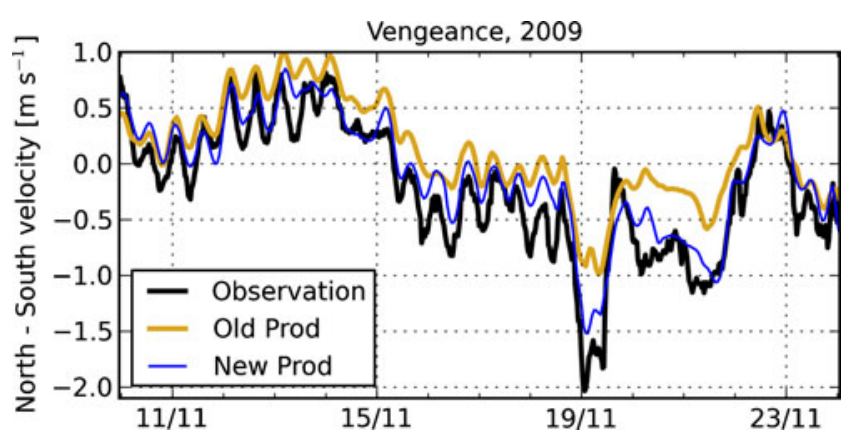

Fig. 6 North-South component of the velocity at Vengeance at $1.0 \mathrm{~m}$ depth observed, Old Prod, and New Prod Observations are from DaMSA (2010b). Model results are from the DK600 setup propagation and damping (results not shown). Thus, it is expected that increased tuning of the bathymetry in the Inner Danish waters could increase the model skill in this area. In addition, slow intrusion of dense waters through the Belt Sea is a delicate process, for which the modeled result depends a lot on the local trenches in the bathymetry and where high gradients in the bathymetry may lead to significant overestimation of the mixing processes. Such baroclinic processes influence the local currents in the Danish straits and ultimately the dense water intrusions into the Baltic Sea. Several areas in the Danish straits are quite narrow or have so complicated bathymetric features that the local currents are affected on scales smaller than the $600 \mathrm{~m}$, which is presently the finest model resolution used at DaMSA. In such areas, the modeled current could improve if further nesting to, e.g., local 200-m models were applied. The ongoing work at DaMSA includes both higherresolution models, local bathymetric tuning of the tidal signal, and better modeling of the trenches and other bathymetric features in the complicated Danish Belt Seas. In the near future, a study of the effect of the choice of weather model is planned.

\section{Conclusions}

Elevation in the inner Danish waters is to a large extent determined by the surge from the northern North Atlantic. The modeled surge that enters the northern North Sea is highly dependent on both the prescribed elevation on the open boundaries and on the type of boundary conditions. The Flather boundary condition forced by a combination of inverse barometric effect and a $0.06 \mathrm{~m}$ amplitude annual steric height works very well for the present configuration. The explained variance of the surge at Wick increases in the present study from $41 \%$ to $90 \%$, and the RMSE decreases from 0.13 to $0.04 \mathrm{~m}$. A minor part of this improvement can be attributed to updates of the GETM source code. In Skagerrak and Kattegat, the explained variance of elevation increases from $70-73 \%$ to $84-90 \%$, or, inversely, the "unexplained" part of the observations is reduced by roughly half.

Infrequent weather patterns may generate currents in the Danish Straits of 1.0 to $2.0 \mathrm{~m} / \mathrm{s}$ over several days. To simulate these strong events, it is important to model the response to both local weather and surge. The changes in the GETM setups presented in this study greatly improve the simulated currents, both for the specific event and for the annual statistical values. The explained variance of the currents at Vengeance increased from $67 \%$ to $88 \%$.

As the Danish Maritime Safety Administration is providing hydrodynamic forecast to improve safety at sea, it is important 
to deliver forecasts which predict both the average situation and the extreme events as accurately as possible.

Acknowledgements The authors thank Dr. Jesper Larsen for model improvements of the NS1C setup, Dr. Johan Mattsson for valuable comments on the manuscript, and Dr. Hannes Rennau for guidance and ideas related to web-based validation systems.

Open Access This article is distributed under the terms of the Creative Commons Attribution Noncommercial License which permits any noncommercial use, distribution, and reproduction in any medium, provided the original author(s) and source are credited.

\section{References}

Andersen O (2006) The ANDERSEN 06 global empirical ocean tide model. Presented AGU WPGM meeting, Beijing, China, July, 2006. Available at http://www.space.dtu.dk/upload/institutter/space/data_og_modeller/ tide/andersen_ag06_tide.pdf. Accessed 17 December 2010.

Beardsley RC (2005) Bobstuff Vector Correlation, Complex Correlation, and other tools. http://woodshole.er.usgs.gov/operations/sea-mat/ bobstuff-html/pl33tn.html. Accessed 4 January 2011.

Beardsley RC, Limeburner R, Rosenfeld LK (1983) In: Limeburner R (Ed) CODE-2: Moored array and large-scale data report. WHOI Technical Report 85-35. Woods Hole, MA, pp 1-21.

BODC (2010) British Oceanographic Data, funded by the Environment Agency and NERC. https://www.bodc.ac.uk/data/online_delivery/ ntslf/processed/. Accessed 14 December 2010.

BOOS (2010) Baltic Operational Oceanographic System, ftp://ftp. boos.org/. Accessed 14 December 2010.
Burchard H, Janssen F, Bolding K, Umlauf L, Rennau H (2009) Model simulations of dense bottom currents in the Western Baltic Sea. Cont Shelf Res 29:205-220

Burchard H, Bolding K, Umlauf L (2010) GETM Source Code and Test Case Documentation Version pre 2.0.x. http://www.getm.eu/ data/getm/doc/getm-doc-devel.pdf. Accessed 14 December 2010

Carter GS, Merrifield MA (2007) Open boundary conditions for regional tidal simulations. Ocean Modelling 18:194-209

COAS (2010) OSU Tidal Data Inversion, http://volkov.oce.orst.edu/ tides/. Accessed: 17 December, 2010.

DaMSA (2010a) Danish Maritime Safety Administration, Sailing forecast http://frv.dk/en. Accessed 14 December 2010.

DaMSA (2010b) Danish Maritime Safety Administration, Fairway measurements http://frv.dk/en. Accessed 14 December 2010.

Egbert GD, Erofeeva SY (2002) Efficient inverse modeling of barotropic ocean tides. J Atmos Oceanic Technol 19(2):183204

Feistel R, Nausch G, Wasmund N (2008) State and Evolution of the Baltic Sea, 1952-2005. Wiley, Hoboken, New Jersey

Hansen C, Söderkvist J (2010) Validation of the DaMSA Sailing Forecast 1/1-31/12 2009, Revision 1. Danish Maritime Safety Administration. http://frv.dk/SiteCollectionDocuments/pdf/ Report DaMSA 2010-01.pdf. Accessed 17 December 2010.

Ivchenko VO, Danilov SD, Sidorenko DV, Schröter J, Wenzel M, Aleynik DL (2007) Comparing the steric height in the Northern Atlantic with satellite altimetry. Ocean Sci 3:485490

Met Office (2010) Floods in Cumbria-November 2009. http://www. metoffice.gov.uk/climate/uk/interesting/nov2009/. Accessed 17 December 2010.

Ponte RM, Salstein DA, Rosen RD (1991) Sea level response to pressure forcing in a barotropic numerical model. J Phys Oceanogr 21:1043-1057 